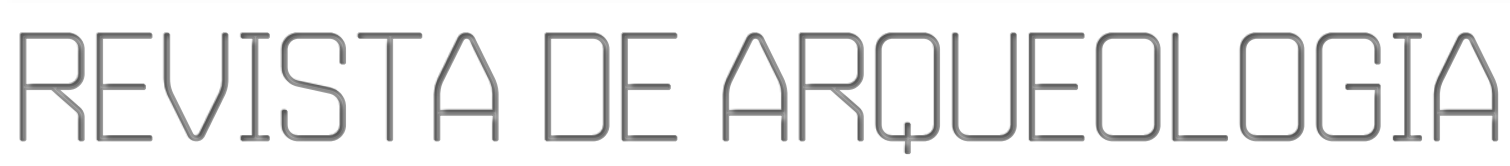

Volume 33 No. 12020

\title{
A TECNOLOGIA LÍTICA À FRANCESA
}

\section{Jacques Pelegrin*}

Tradução: Maria Jacqueline Rodet ${ }^{\star *}$, Déborah Duarte-Talim ${ }^{\star * *}$

\section{RESUMO}

O estudo das indústrias líticas pré-históricas foi modernizado na França há quase 40 anos, graças à sinergia da problemática paleoetnológica de André LeroiGourhan e dos avanços metodológicos de Jacques Tixier. Assim, da tipologia tradicional, passou-se à apreciação dos comportamentos técnicos e econômicos dos grupos humanos pré-históricos. Mais recentemente foram integradas também noções da psicologia (conhecimento e savoir-faire, natureza das intenções) que permitem um enriquecimento qualitativo e interpretativo, como a detecção de aprendizes e especialistas, a "purificação" das formas de ver e de fazer, a identificação de prioridades, além das hipóteses explicativas sobre certas mudanças. Trata-se de uma conferência realizada durante a XIX Reunião da SAB, em Teresina, em setembro 2017.

Palavras-chave: Tecnologia Lítica; Metodologia; Escola Francesa.

* CNRS UMR 7055 "Préhistoire et Technologie". Maison Archéologie Ethnologie. 21, avenue de l'université 92023, Nanterre cedex, France. E-mail: jacques.pelegrin@cnrs.fr. ORCID: https://orcid.org/0000-0002-0671-128X.

** Departamento de Antropologia e Arqueologia, Universidade Federal de Minas Gerais. Av. Pres. Antônio Carlos, 6627 - Pampulha, Belo Horizonte - MG, 31270-901, Brasil. E-mail: mjrodet.ufmg@gmail.com. ORCID: https://orcid.org/0000-0001-5742-5999.

*** Museu de História Natural e Jardim Botânico da Universidade Federal de Minas Gerais. R. Gustavo da Silveira, 1035 - Santa Inês, Belo Horizonte - MG, 31080-010, Brasil.

E-mail: delsduarte@hotmail.com... ORCID: https://orcid.org/0000-0002-5470-3364. 


\section{A FRENCH SCHOOL OF LITHIC TECHNOLOGY}

\section{ABSTRACT}

The study of prehistoric lithic industries was much modernized in France about 40 years ago, thanks to the synergetic ambition of André Leroi-Gourhan (palethnology), and the methodological advances of Jacques Tixier. It has thus passed from the traditional typology to the appreciation of technical and economic behaviors of the prehistoric human groups. More recently, it has also integrated notions from psychology (knowledge and savoir-faire, nature of intentions) that allow a qualitative and interpretative enrichment, such as the detection of apprentices and specialists, the "purification" of the "ways of seeing and doing", the identification of priorities and explanatory hypotheses about certain changes. This text is that of a conference given in Teresina during the 19th meeting of the SAB, September 2017.

Keywords: Lithic Technology; Methodology; French School.

\section{LA TECNOLOGÍA LÍTICA A LA FRANCESA}

\section{RESUMEN}

El estudio de las industrias líticas prehistóricas se modernizó en Francia hace casi 40 años, gracias a la ambición paleo-etnológica de André Leroi-Gourhan, y los avances metodológicos de Jacques Tixier. Así, ha pasado da tipología tradicional, al nivel de los comportamientos técnicos y económicos de los grupos humanos prehistóricos. Recientemente, también se han integrado nociones de la psicología (conocimiento y savoir-faire, intenciones) que permiten un enriquecimiento cualitativo e interpretativo, como la detección de aprendices y especialistas, la "purificación" de las formas de ver y hacer, la identificación de prioridades e hipótesis explicativas sobre ciertos cambios. Se trata de una conferencia realizada em Teresina durante la XIX Reunión de la SAB, em septiembre 2017.

Palabras clave: Tecnología lítica; Metodología; Escuela Francesa. 


\section{PROLOGO}

Durante a sua segunda estada no Brasil como professor convidado pela Universidade Federal de Minas Gerais, no mês de março de 2017, Jacques Pelegrin, diretor de pesquisa no organismo francês CNRS (Centro Nacional de Pesquisa Científica), foi convidado para fazer a conferência de encerramento da XIX Reunião da Sociedade de Arqueologia Brasileira (SAB), na cidade de Teresina, Piauí, pela iniciativa da Professora Mariana Cabral e do Presidente da SAB, professor Flávio Calippo. Pediuse ao convidado uma explanação sobre os princípios da tecnologia lítica, ou de maneira mais ampla, dos estudos das indústrias líticas, tal como ela é praticada na França atualmente, disciplina que J. Pelegrin ensina em seu país e em outros há mais de 30 anos $^{1}$. $\mathrm{O}$ presente artigo retoma o texto da conferência traduzido, adaptado e complementado.

\section{INTRODUÇÃO}

A abordagem francesa das indústrias líticas foi consideravelmente modernizada desde os anos 1980, permitindo assim o tratamento de novas problemáticas. Neste artigo veremos alguns exemplos disso. A abordagem se modernizou, mas guardou algumas especificidades, notadamente em relação aos nossos colegas anglo-saxônicos (PERLÈS, 2016). É importante iniciar este texto falando brevemente das raízes dessa modernização, pois todas as ideias possuem uma história.

$\mathrm{Na}$ França, o interesse pelos aspectos tecnológicos se manifestou desde o aparecimento da noção de pré-história, no sentido de melhor conhecer como as pedras lascadas foram produzidas pelos nossos ancestrais e em que isso poderia implicar. Foi assim que Jacques Boucher de Perthes (BOUCHER DE PERTHES, 1849) atribuiu aos grupos humanos muito antigos, certamente antediluvianos, a produção de bifaces em sílex encontrados em sedimentos profundos, ao lado de ossos de animais desaparecidos, como o mamute, no norte da França. Ele reconheceu esses bifaces como frutos de uma técnica elaborada de lascamento que só poderia ser resultante de atividades humanas.

As lâminas de machado polidas, já comparadas pelo naturalista B. Jussieu, em 1723, a lâminas etnográficas do Canadá e da Caribe, são reconhecidas como produtos técnicos pré-históricos (o que já havia sido dito pelo italiano Mercati no final do século XVI), anteriores ao metal, uma vez que uma crença popular, como no Brasil, as considerava como pedras que caíam do céu (os coriscos), ou seja, pedras criadas pelos relâmpagos.

Alguns dos primeiros arqueólogos europeus, como o francês H. Muller (MÜLLER, 1903) e o dinamarquês N.F.B. Sehested (SEHESTED, 1884), tentavam entender sua reprodução, mas os protocolos são imprecisos ou mesmo errôneos, como, por exemplo, a utilização da areia para polir o sílex, quando, na verdade, a areia não foi utilizada por ser ineficaz.

Pelo menos os lascadores de pederneiras em sílex, ainda em atividade até o início do século XX, na França e na Inglaterra, foram uma fonte muito útil para os primeiros préhistoriadores. É a partir de sua observação que provêm os primeiros termos descritivos de objetos lascados: lasca, lâmina, talão, bulbo concoidal, face inferior ou de lascamento e núcleos. Isso foi importante para reconhecer as peças lascadas e os dejetos de lascamento pré-históricos, descrevê-los e desenhá-los.

\footnotetext{
${ }^{1}$ Devemos ao Professor André Prous da Universidade Federal de Minas Gerais a criação dos primeiros laços entre o Brasil e o laboratório de Prehistoire et Technologie du CNRS e da Universidade de Paris-Nanterre, fundado e dirigido na época por Jacques Tixier, de quem ele era amigo. Nos anos 1980, A. Prous convida J. Tixier a ministrar algumas semanas de curso na UFMG. Finalmente, um dos os frutos dessa relação será a chegada de vários estudantes brasileiros ao laboratório: Solange Caldarelli, Emilio Fogaça, Mônica Schlobach, Maria Jacqueline Rodet e mais recentemente, Juliana de Resende Machado e Déborah Duarte-Talim.
} 
Os testemunhos etnográficos de povos indígenas que ainda lascavam a pedra no momento da chegada dos colonizadores ocidentais interessaram a alguns arqueólogos, como o erudito inglês John Evans (EVANS, 1872-1878). Esses testemunhos poderiam ter sido de grande utilidade, mas foram muito sucintos em suas descrições, amputados de detalhes importantes, no momento de suas transcrições de segunda ou terceira mão. A produção indígena de utensílios de pedra desapareceu muito rapidamente quase em todo lugar, substituída por instrumentos metálicos. É por isso que não dispomos praticamente de nenhuma coleção de objetos lascados etnográficos acompanhados de seus instrumentos de lascamento e de descrições de sua produção.

De toda maneira, esse interesse que certos pré-historiadores têm pelos aspectos técnicos dos instrumentos de pedra vai acabar durante o século $\mathrm{XX}$, a favor da problemática crono-cultural.

Em uma Europa continental então muito nacionalista, a prioridade absoluta foi identificar os povos através de suas culturas materiais, das características de seus raros esqueletos e de reconhecer os territórios, com uma intenção subjacente de justificação ou reivindicação histórica, como ainda é o caso em certos países.

Os primeiros arqueólogos, de fato paleontólogos, distinguiam grandes períodos a partir de restos faunísticos: idade do urso da caverna, idade da rena, etc. Com isso, foram identificados então como fósseis guias, certos instrumentos, emblemáticos de "culturas", como os bifaces do Acheulense, pontas do Gravettiense, folhas louro do Solutrense, etc. Essas "culturas" foram consideradas como a marca de "povos" que se sucederam ou que dividiram "territórios" ao longo dos séculos, ou mesmo dos milênios, quando não se dispunha ainda de datas absolutas.

O sudoeste da França, mais particularmente na região da Dordonha, que, devido a uma abundância de sítios do período paleolítico em contexto cárstico de abrigos e de grutas, relativamente bem conservados e fáceis de se encontrar, acabou sendo o ponto de origem e de referência de culturas paleolíticas europeias, dentro de uma visão excessivamente "etnicista".

Desde os anos 1950, mesmo com a modernização feita por François Bordes, o estudo de uma coleção lítica consistiu, até os anos 1970, em descrever as peças retocadas e façonadas (os "instrumentos") e em classificá-las dentro de "tipos" pré-definidos (raspador convexo ou côncavo, raspadeira sobre lâmina, buril diedro, etc.). Este método permitiu criar um diagrama acumulativo sobre o qual eram transferidas outras coleções de composição mais ou menos diferentes. A partir daí, discute-se a semelhança ou a diferença entre elas, consideradas diretamente como uma proximidade ou uma distância "cultural". Isso com o objetivo de distinguir as culturas ou suas variantes regionais e/ou de especificar o lugar de cada coleção em uma linha evolutiva regional ou continental.

Essa problemática que podemos chamar de "crono-cultural clássica" foi legítima e ainda o é. Entretanto, é verdade que, assim limitado, o estudo parecia de certa maneira desumanizado.

Duas novas correntes de pensamento vieram ampliar as problemáticas da pesquisa. A primeira deve-se a André Leroi-Gourhan (AUDOUZE \& SCHLANGER, 2004; SCHLANGER, 2005). Na linha de etnólogos como Marcel Mauss (1947) e Marcel Maget (1953), que tinham o interesse de um melhor conhecimento das atividades técnicas das sociedades humanas e que introduziram a noção de cadeia operatória, André LeroiGourhan inicialmente elaborou classificações de técnicas e modos de produção a partir de uma base etnográfica. Em seguida, ele decidiu aplicar essa abordagem em vários sítios arqueológicos, a fim de reconstituir as atividades técnicas de seus ocupantes. Para isso, além dos princípios da escavação horizontal (já praticada por pesquisadores russos - cf. VASIL'EV, 2011), ele refinou a noção de "cadeia operatória" que designa as diferentes 
etapas de transformação de uma matéria, desde sua aquisição até o abandono ou o consumo de seus produtos através de diferentes ações e gestos técnicos.

Do mesmo modo, André Leroi-Gourhan expandiu a problemática "paleoetnológica", que consiste em se interessar não somente pelos instrumentos característicos de um grupo, mas pelo seu comportamento dentro do sítio e no seu entorno. Pouco lhe importava, de fato, que os ocupantes pré-históricos do sítio arqueológico de Pincevent pertencessem ou não ao que foi denominado de Magdaleniense superior. $O$ que lhe interessava era o que tinham feito: como eles tinham praticado a caça, o lascamento e a utilização de seus instrumentos de pedra, de osso; como eles haviam organizado e ocupado as estruturas de seu acampamento. Enfim, como eles se comportavam.

Esta ambição motivou a renovação da pesquisa dos raccords e remontagens líticas pelos seus estudantes Claudine Karlin e Pierre Bodu e também pelo colega belga Daniel Cahen. Com o objetivo de dinamizar a percepção dos solos de habitação e da dimensão espacial das atividades líticas, a partir de então acessíveis em sítios a céu aberto, tais como Pincevent e Meer, escavados por grandes decapagens horizontais (CAHEN et al., 1980). Paralelamente, a equipe de etnólogos do laboratório de Techinique et Culture e editores da revista de mesmo nome e dirigida por Robert Cresswell, desenvolveu numerosas análises etnológicas baseadas no conceito de cadeia operatória, notadamente Pierre Lemonnier (LEMONNIER, 1992).

A segunda corrente, inicialmente mais prática e metodológica, é essencialmente ligada a Jacques Tixier. Com uma experiência pessoal de lascamento de rochas duras, tais como o sílex da Europa e da África do Norte - e mais a experiência de François Bordes -, Jacques Tixier trouxe em primeiro lugar uma distinção fundamental entre método e técnica (TIXIER, 1967), de que falaremos mais tarde, e também um refinamento da terminologia tecnológica lítica, o que é essencial para a disciplina. Isso foi feito com o manual Pré-história da Pedra Lascada (1ª Edição de 1980, $2^{\circ}$ edição de 1995, também traduzida para o inglês e o japonês e atualmente traduzido para o português, com atualizações e com elementos da arqueologia brasileira - 2017, tradução M.J. Rodet e J. Machado).

Nesse sentido, Jacques Tixier enriqueceu, na prática, a aplicação da noção de cadeia operatória aos estudos das indústrias líticas, o que reuniu em torno dele um grupo de pesquisadores, inclusive vários deles pertencentes a outras equipes e que finalmente abriram uma nova perspectiva de análise: a perspectiva econômica (TIXIER [org.], 1980).

Assim, J. Tixier, em l'Aïn Dokkara (TIXIER, 1976), e sua aluna Marie-Louise Inizan (INIZAN, 1984) demonstraram, em 1976, que, no período que é denominado Capsien superior, na África do Norte, os micrólitos em forma de trapézios foram produzidos a partir das lâminas mais regulares, debitadas por pressão, o que os levou a pensar que a debitagem por pressão estava relacionada à intenção de produção dos micrólitos. Nesse momento, os pesquisadores pensaram que esse tipo de lascamento havia sido inventado pelos Capsiens, justamente para fabricar os trapézios (sabe-se hoje que é pouco provável que esta invenção tenha sido local - cf. PELEGRIN, 2012a: 496; de fato, a debitagem por pressão praticada bem antes no norte do Mediterrâneo oriental, acompanhou a introdução da produção de trapézios na África do Norte).

Assim, nascia a noção de "economia de debitagem", que quer dizer que podemos esperar que certos tipos de suporte tenham sido procurados para a realização de certos tipos de instrumentos, abrindo a noção de "regras de gestão de suportes debitados".

Catherine Perlès, em seu estudo sobre o período Neolítico de Franchitti, na Grécia, notou que os pré-históricos tinham tratado os distintos materiais líticos que eles utilizavam, de acordo com os distintos objetivos e modalidades: dizendo de outra 
maneira, eles tinham uma economia da debitagem, mas também uma economia diferenciada de matérias-primas (PERLÈS, 1980:37-41; 1990).

A noção de economia de instrumentos, ou seja, as diferentes etapas da vida de um instrumento, desde seu estado novo, inicial, até o seu abandono, após reavivagens e transformações, etc., veio paralelamente (CAHEN et al., 1980; BINDER \& PERLÈS, 1990) potencializada pelos progressos contemporâneos das análises traceológicas (SEMENOV, 1964; KEELEY, 1980).

A noção de economia das matérias-primas foi então expandida a partir da questão do aprovisionamento da matéria-prima. Curiosamente, mesmo que certos préhistoriadores, como François Bordes, conhecessem bem as matérias-primas líticas lascadas e suas localizações dentro das regiões de pesquisa, eles haviam negligenciado esse potencial.

Foi durante os anos 1980 que os estudos regionais sistemáticos começaram a identificar as jazidas e as características das matérias-primas disponíveis em certas regiões da França, com o objetivo de estudar suas explorações pelos grupos préhistóricos. Essa abordagem permitiu introduzir as noções de território de aprovisionamento ou território frequentado e de estratégia ou modalidade de exploração desse território, via o deslocamento constatado de objetos líticos desde sua jazida natural.

Essa pesquisa começou lentamente, região por região, e às vezes por prospecções e por caracterizações petrográficas. Identificar as matérias-primas locais no entorno do sítio era fácil. Identificar os materiais ainda desconhecidos ou mais distantes implicou na constituição de litotecas regionais, acessíveis a pesquisadores estrangeiros.

Foi assim que depois de 20 anos foi possível reconhecer, para o período Paleolítico, os deslocamentos de um único objeto a centenas de quilômetros de distância, por exemplo, entre a Espanha e França, nos Pirineus. Além disso, para o período Neolítico, Pierre Pétrequin pôde demonstrar a difusão em toda a Europa de lâminas de machado em jadeíta, cujas jazidas ele havia encontrado nos Alpes do Sul (GAUTHIER \& PÉTREQUIN, 2017).

O interesse econômico e/ou sociológico desse tipo de informação é tão grande, que ele justifica a pesquisa de longa duração, pelo menos para os materiais não banais. No Brasil, se o quartzo (e o cristal), de uma maneira geral, e os quartzitos são largamente disponíveis, o sílex e certos silexitos merecem ser procurados, como por exemplo as matérias-primas das pontas de projéteis do estado do Rio Grande do Norte, que estão hoje no museu da cidade de Mossoró, ou, ainda, a matéria prima da ponta de projétil encontrada recentemente em Itamarandiba, estado de Minas Gerais (RODET et al., 2013).

É assim que, durante os anos 1980, as questões ou problemáticas da pesquisa foram profundamente renovadas nos seus aspectos técnico-econômicos e comportamentais; quando possível, no próprio sítio arqueológico (estudo das estruturas, das distintas zonas de atividades, etc.) ou, de uma maneira mais ampla, no contexto ambiental do sítio. Essa renovação deve muito pouco à arqueologia Americana, mesmo que ela estivesse em pleno desenvolvimento com Lewis Binford, de uma perspectiva similar, com a noção de Technological Organization. Os americanos influenciaram os franceses muito mais sobre as questões de processos tafonômicos (fenômeno pós-deposicional que afeta tanto os sítios como os vestígios), de formação dos sítios arqueológicos e sobre a modernização do estudo de restos faunísticos. À clássica paleontologia e cronoclimatologia foram acrescidas às problemáticas modernas, comportamentais, da arqueozoologia - isso também graças a Lewis Binford. Como exemplo, podemos citar práticas de caça e eventual seleção, do animal, exploração alimentar e técnica do animal - isso também segundo a trama da cadeia operatória. 
Finalmente, a noção de cadeia operatória é muito simples e seu interesse é metodológico: considerar as atividades técnicas de grupos e indivíduos pré-históricos como "cadeias operatórias", quer dizer, encadeamento de gestos e operações técnicas, da aquisição da matéria-prima ao abandono ou consumo final de seus produtos. Falamos bem: "cadeias operatórias", no plural, pois pode-se ter várias cadeias operatórias em uma mesma coleção, entendendo-se que uma cadeia operatória (desde o elemento bruto de rocha lascável) se define, na prática, como um caminho para se obter uma classe ou gama de produtos.

Nas indústrias mais complexas que conhecemos na Europa, pode-se ter várias cadeias operatórias independentes, por exemplo: debitagem de lascas Levallois e debitagem de pequenas lâminas, em um nível Musteriense antigo do sítio de Riencourtles-Bapaume (TRUFFEAU, 1993), do norte da França e mesmo três produções diferentes no Solutrense superior do sítio Maîtreaux (AUBRY et al., 1998). Em outros casos frequentes, duas cadeias operatórias são "ramificadas", que significa que certos subprodutos de uma cadeia operatória servem para produzir outra cadeia operatória. Por exemplo: as grossas lascas de entame de debitagem de lâminas (cadeia operatória principal) são utilizadas para produzir lamínulas (cadeia operatória ramificada). Outras ainda são mais discretas, como a retomada de certas grandes lascas ou núcleos rejeitados, para retirar pequenas lascas que serão utilizadas brutas de lascamento.

No Brasil, é frequente a presença de várias cadeias operatórias em uma mesma coleção, ou, pelo menos, várias matérias-primas representadas, por vezes bem diferentes, como, por exemplo, os seixos de quartzo e/ou quartzito, grandes fragmentos de arenito silicificado, cristais de quartzo ou nódulos de silexito.

\section{PRIMEIRAS IMPLICAÇÕES METODOLÓGICAS}

A primeira etapa do estudo consiste, então, em identificar a ou as cadeias operatórias representadas dentro do conjunto a ser estudado (séries ou coleções), isso após uma primeira subdivisão por variedade de matéria-prima. Essa identificação requer, por vezes, uma boa leitura tecnológica e conhecimentos preliminares.

A leitura tecnológica, sistematizada por Jacques Tixier et al. (1980), com a colaboração do grafista Michel Dauvois, consiste no reconhecimento:

- da natureza da peça (lasca ou fragmento, núcleo, peça façonada, esquilha, ou seixo fraturado em Split, etc.);

- da natureza de cada faceta visível sobre uma peça: porção da superfície natural ou cortical, a parte positiva da lasca (face inferior), o negativo da retirada, ou ainda de fraturas durante o lascamento;

- da direção e da ordem dos negativos visíveis sobre a peça²;

- se estamos diante de uma lasca ou de uma esquilha, o que levará o pesquisador a procurar em seguida toda a modificação posterior ao lascamento, ou seja, o retoque, uma fratura, etc.

\footnotetext{
${ }^{2}$ Isto é possível, na quase totalidade dos casos, em função de que toda fratura de lascamento realizada pelo Homem é uma fratura orientada, desde o seu ponto de origem (bem claro pela presença do bulbo ou pelo esmagamento determinado pelo impacto), seguido pela propagação marcada por ondulações e uma seção transversal levemente curva: convexa sobre o elemento destacado e côncavo em seu negativo (sobre a peça lascada). Por outro lado, os bordos de uma lasca são geralmente marcados por lancetas obliquas. Mesmo se a peça é somente um fragmento de lasca que perdeu sua extremidade proximal (então seu talão e seu bulbo), ainda é possível, seguindo a curvatura da seção, as ondas e eventuais lancetas, determinar a sua natureza de fragmento de lasca e a sua direção original.
} 
Essa leitura tecnológica de cada peça dentro de uma coleção não leva mais do que alguns segundos para um tecnólogo lítico experiente ou para um estudante bem formado. No entanto ela pode tomar muito tempo, no caso de um estudante em formação.

A leitura tecnológica permitirá uma primeira triagem da coleção, subdividindo, por matéria-prima:

- os núcleos;

- as peças façonadas;

- todas peças retocadas, no sentido tradicional de instrumento;

- todas as peças mais ou menos "alteradas", ou seja, com macrotraços de possível utilização;

- todos os outros, ou seja, os restos brutos de lascamento e seus fragmentos e ainda os elementos naturais conservados, por dúvida, durante a escavação.

Os conhecimentos preliminares vão permitir definir a ou as cadeias operatórias representadas graças às observações realizadas no momento dessa primeira classificação:

- A observação das peças retocadas e com macrotraços e também dos núcleos deveria já ter indicado uma grande parte os objetivos do lascamento. Na França, para o período Paleolítico superior, podemos encontrar, a partir dos instrumentos, vários tipos de suportes (por exemplo, algumas classes de lâminas ou, pelo menos, uma classe de lamínulas) e, para o Paleolítico médio, pelo menos, duas classes de lascas, o que é provavelmente um caso frequente no Brasil.

- Eventualmente façonagem, identificável através das peças façonadas inteiras ou fragmentadas, mas também, em sua ausência, a partir do reconhecimento de certos restos elementos brutos de lascamento que são característicos, como as lascas pouco espessas de façonagem bifacial e, no Brasil, as lascas características de façonagem ou reavivagens de instrumentos de secção plano-convexa (PROUS et al., 1994; FOGAÇA, 2001; RODET, 2006).

No contexto da exploração das matérias-primas líticas lascáveis, essa abordagem é facilitada, pois se trata de um processo de redução (redução de um núcleo equivale à debitagem, redução de bloco em biface ou lâmina equivale à façonagem), no qual alguns restos e/ou produtos e subprodutos de cada etapa são facilmente identificáveis.

A noção de conhecimentos preliminares se compreende então muito bem, pois podemos reconhecer somente o que aprendemos a conhecer e aquilo que compreendemos. É por isso que damos muito mais importância, na França, em relação aos países anglo-saxônicos, à formação prática em tecnologia lítica, com observações, esquemas e desenhos de peças líticas variadas, naturais e antrópicas, arqueológicas ou experimentais. Ou ainda à prática da remontagem de séries experimentais. Os estágios de iniciação de prática ao lascamento são também de grande interesse, pois estes formam ativamente os estudantes na leitura tecnológica e "nos conhecimentos gerais".

Voltemos então à noção de cadeia operatória que, juntamente com a leitura tecnológica de Jacques Tixier, transformou-se na França, na base do estudo de coleções líticas, estruturando a classificação "tecno-econômica" de conjuntos de restos e de produtos de lascamentos encontrados em um sítio arqueológico, com o estudo e a apresentação dos dados e informações ${ }^{3}$.

\footnotetext{
${ }^{3}$ Entretanto esta noção não obriga a estudar ou a apresentar os fatos segundo a ordem desde a aquisição até o abandono, ainda que seguidamente a utilização precisa de objetos líticos seja de fato ignorada ou somente presumida. Argumentamos
} 
Essa classificação tecno-econômica constitui, segundo nossa abordagem francesa, a primeira etapa de estudo, uma vez reconhecida(s) a ou as cadeias operatórias representadas dentro do sítio estudado. Ela pode ser sintetizada, como fez Jean-Michel Geneste (1985), pela primeira vez, através de um diagrama em colunas. Cada coluna indica em número ou em peso uma classe de peças representativa de uma etapa identificável de cada cadeia operatória, o que deverá ser adaptado, segundo cada coleção. Testes experimentais bem conduzidos podem ajudar a refinar essas "normalidades", reproduzindo estritamente a cadeia operatória arqueológica com a mesma gama de matérias-primas.

Esses dados, assim evidenciados, ensinam bem sobre os aspectos tecno-econômicos, ao pontuar as atividades líticas realizadas no sítio: o estado em que chegaram as diferentes matérias-primas e o tratamento recebido pelos materiais, e em até que ponto eles foram tratados, etc. Entretanto é difícil determinar se certas peças foram levadas dos sítios.

Trata-se de uma primeira fase de estudo que é simples, se dispomos de uma boa leitura tecnológica e de conhecimentos preliminares para identificar cadeias operatórias representadas.

\section{DESENVOLVIMENTO QUALITATIVO}

Muitos avanços enriqueceram qualitativamente a noção de cadeia operatória. Esses avanços vão permitir caracterizar minuciosamente a indústria estudada. $\mathrm{O}$ primeiro deles é aquele da distinção entre método e técnica proposta, como já mencionado, por Jacques Tixier (1967). De fato, aquilo que os americanos chamam globalmente de "The technique", Jacques Tixier distinguiu, por um lado, método e, por outro, técnica.

$\mathrm{O}$ método pode ser definido como uma abordagem sistematizada e mais ou menos racional que seguimos para atingir um objetivo. Designa ainda a ordem e o agenciamento de conjuntos de retiradas efetuados sobre um bloco de matéria-prima debitado ou façonado, ou ainda no momento de retoque de um instrumento. Trata-se de agenciamentos específicos que permitem, no mesmo bloco debitar toda uma série de lascas: segundo uma "fórmula" simples; retirar uma ou mais lascas do tipo Levalllois, após a formatação específica; debitar lâminas largas e arqueadas, ou, ao contrário, estreitas e de perfil retilíneo. Ou, ainda, façonar um picão triédrico, uma lâmina de secção biconvexa ou quadrangular, ou uma folha de louro.

Os métodos de lascamento são reconhecidos através da leitura tecnológica acurada do conjunto de peças lascadas, que fornecem informações complementares: peças façonadas em diversos estados técnicos e lascas de façonagem, núcleos em diversos estados técnicos e seus produtos e subprodutos.

As experiências de lascamento não podem substituir a leitura tecnológica, mas um treinamento de leitura tecnológica sobre séries experimentais pertinentes ajuda na leitura de restos e de produtos característicos de métodos de façonagem e de debitagem.

De fato, um método de lascamento foi aplicado durante a pré-história e deve então ser compreendido pelos arqueólogos em coerência com a forma e com as qualidades da matéria-prima escolhida ou disponível. Levando em conta a variabilidade da matériaprima e as eventualidades do lascamento, procuraremos o "princípio gerador" (fórmula simples de encadeamento ou a procura de uma morfologia particular), pois não deveríamos encontrar mais do que alguns métodos para uma mesma cadeia operatória.

assim sobre o interesse durante o estudo de uma coleção lítica, de iniciar pela caracterização de instrumentos, em particular de seus suportes que ensinam diretamente sobre os objetivos da debitagem. 
A técnica, por sua vez, no sentido restrito de Jacques Tixier, designa o modo prático da ação sobre a matéria, ou seja, da execução prática de retiradas ao longo de uma cadeia operatória ou de uma sequência específica.

Atenção! Existem cadeias operatórias arqueológicas em que diferentes técnicas são utilizadas (cinco técnicas diferentes podem ser aplicadas em uma mesma cadeia operatória, como no período Chasséen), o que implica primeiramente em compreender e classificar os restos de diferentes etapas antes de procurar precisamente sua técnica respectiva.

Uma vez reconhecido o mecanismo de fratura, afinal existem dois - a fratura concoidal e a fratura em Split -, uma técnica pode ser caracterizada, a partir de:

- primeiramente, o modo de aplicação da força (percussão direta, indireta, pressão);

- em seguida, a natureza e a forma dos instrumentos de lascamento (percutores de pedra dura, macia, orgânico de madeira dura ou de chifre de cervídeo, ponta de pressão orgânica ou de cobre, etc.);

- e, ainda, os parâmetros gestuais, como a posição do corpo e o modo de manter ou segurar a peça a ser lascada, que são por vezes acessíveis através do material arqueológico.

Contrariamente aos métodos de lascamento, o reconhecimento de técnicas arqueológicas pôde ser feito através das experimentações: as técnicas são como fantasmas, ou seja, não são nunca visíveis no material arqueológico, salvo se existe um referencial experimental. Nós não veremos jamais os gestos nem os instrumentos de lascamento, os quais são raramente conservados e identificados; as técnicas não poderão ser reconhecidas, a não ser por comparação com um referencial moderno e bem documentado. Ressalta-se inclusive que, mesmo que elaborada para o lascamento, essa distinção se aplica muito bem à tecnologia óssea e à cerâmica, como bem demonstra o novo trabalho de Valentine Roux $(2016,2019)$.

Assim, graças à leitura tecnológica desenvolvida por Jacques Tixier, como supracitado, a leitura fina dos métodos de lascamento utilizados em diversas coleções demonstrou sua grande riqueza potencial. Até o momento, foram descritos pelo menos dez métodos de debitagem de lâminas para o Paleolítico superior na França, dentre os quais a maior parte é especifica de um período preciso (sobre pequeno núcleo, raspador caréné, raspador à museu, buril de Vachons, buril de Raysse, pseudo-denticulado do Protosolutrense, Bertonne, Orville, Rocher de la Caille, La Marche, ou sobre núcleo quadrangular). E, uma vez que falamos indiferentemente "da" debitagem de lâminas do Paleolítico superior, pode-se atualmente distinguir pelo menos seis versões bem características (proto-Aurignaciense, Aurignaciense antigo, Gravettiense com pontas gravettes, Gravettiense evoluído em pluri-produtos, Solutrense antigo, Magdalense médio-superior), pelo menos no sudoeste da França, onde os distintos tipos de sílex disponíveis permitem tal expressão (PELEGRIN, 2012b).

As técnicas de lascamento, por vezes difíceis de serem reconhecidas (TIXIER, 1982), se beneficiaram de uma sistematização tardia da "experimentação" ou, melhor dizendo, da prática moderna do lascamento (PELEGRIN, 1991). Essa prática demonstrou que de fato há cinco técnicas, com seus respectivos caracteres distintos e, portanto, diagnósticos (PELEGRIN \& TEXIER, 2004; PELEGRIN, 2000, 2012a). São elas: percussão direta no interior do plano de percussão, realizada com pedra dura; percussão direta orgânica tangencial; percussão direta tangencial com pedra macia; percussão indireta e pressão com cinco modos diferentes. Esse é, talvez, um campo de pesquisa que é exclusivamente francês. 
Inicialmente isoladas, e aparentemente anedóticas, essas imprecisões modernas relacionadas aos métodos e às técnicas de lascamento contribuem muito para enriquecer a caracterização de coleções e de indústrias e nos permitem distinguir melhor as inovações e analisar a parte relativa aos conhecimentos e ao savoir-faire. Os conhecimentos são visíveis e facilmente transmissíveis, como a ideia da agulha. Entretanto os savoir-faire, invisíveis, são mais dificilmente transmissíveis. Isso nos conduz, então, para novas perspectivas: distinção de tradições, difusão de ideias técnicas, deslocamentos de indivíduos ou de grupos. Por exemplo, as peças foliáceas com coches clactonianos do Rio Grande do Norte (RODET et al., 2013; RODET \& PELEGRIN, no prelo) implicam uma técnica particular, a qual a invenção múltipla independente é pouco provável. Ou seja, elas se inscrevem provavelmente dentro de uma mesma tradição, e talvez, em uma mesma linhagem de lascadores que necessita ainda ser restituída no tempo e no espaço.

Outro avanço metodológico também proveniente da noção de cadeia operatória é aquele do estado técnico das peças, magistralmente percebido por Holmes desde o início do século XX (HOLMES, 1919), mas ainda frequentemente negligenciado.

O estado técnico de uma peça façonada, de um núcleo, um instrumento ou fragmento retocado, corresponde ao momento da cadeia operatória no qual esta peça foi abandonada e chega nas mãos do pré-historiador. De fato, essa parada e abandono podem acontecer em diferentes momentos da cadeia operatória, se bem que objetos de aspectos muito diferentes são, de fato, a expressão de um mesmo objetivo, mas em estado técnico (e tecno-econômico) diferente. Assim, a mesma cadeia operatória de produção de uma peça façonada foliácea pode ser encontrada no estado de esboço ou de pré-forma mais ou menos avançada, intencionalmente quebrada, como também no estado de fragmento de uma peça aparentemente terminada (pouco espessa, com bordos regulares), ou de fragmento retomado, retrabalhado e deformado. Na realidade, inclusive, esses diferentes estados técnicos são observados bem mais frequentemente do que o objeto inteiro típico. Nos sítios de habitação do período Paleolítico, poucos núcleos são encontrados em bom estado: a maior parte deles foi retomada e deformada por acidentes que ocorreram na fase final de lascamento, e a maior parte das folhas de louro solutrenses, por exemplo, é quebrada durante o lascamento e deformada, ou retomada com pouca habilidade.

A ignorância ou a negligencia dessa noção traz, por vezes, uma grande perda de tempo, como no caso dos "bifaces Chivateros", da costa norte do Peru, onde certos pesquisadores viram bifaces evocadores de um Paleolítico antigo, quando, de fato, tratase simplesmente de estar perto de afloramentos da matéria-prima explorada, de esboços abandonados, quebrados ou desviantes, segundo a boa expressão de Claude Chauchat (CHAUCHAT et al., 1992). O termo "desviantes" significa que as peças não podem ser terminadas em pontas foliáceas do tipo "ponta de Paijan", pois são muito espessas, acidentadas por um profundo refletido ou com um bordo esmagado, dito de outra forma, peças que saíram - desviantes, anormais - da cadeia operatória normal.

Essa noção de estado técnico nos parece pertinente e poderia ser aplicada em muitas indústrias líticas brasileiras, em particular para os seixos lascados abandonados prematuramente, as pontas de projétil e os instrumentos façonados de secção planoconvexa. Efetivamente mais recentemente essa noção tem sido aplicada nos estudos dos plano-convexos antigos do Brasil Central (FOGAÇA, 2001; RODET, 2006; BUENO, 2007; LOURDEAU, 2010; RODET et al., 2019 - ressalta-se que três dentre esses autores foram formados na França). Esses últimos, mais especificamente, podem ser encontrados em diferentes estados de reavivagem (frontal e/ou lateral), quando se trata de instrumentos, mas também em diferentes estados de retomada, se eles serviram de núcleos para a obtenção de lascas pouco espessas e muito cortantes. 
Na problemática dos seixos lascados, temos uma bela experiência, relacionada a uma coleção nos antigos terraços do rio Garonne, na França. Neste contexto, poderiam ter sido vistos pelo menos quinze tipos de instrumentos, segundo o número e a disposição das retiradas. Entretanto de fato eles eram resultantes de somente três cadeias operatórias em diferentes estados técnicos: primeiro, principalmente debitagem de lascas; segundo, produção de alguns instrumentos, sobre seixos de quartzito, do tipo chopper, com regularização do bordo ativo, ou seja, com tentativas de produção de verdadeiros instrumentos façonados, mas abandonados ou rejeitados in situ depois de utilizados; e, terceiro, núcleos sobre seixos de quartzo leitoso, debitados por fratura em Split, sobre bigorna, produtores de fragmentos de quartzo pouco espessos e muito cortantes. Em cada cadeia operatória, os objetos foram abandonados muito cedo, em função de uma matéria-prima de má qualidade, granulosa ou fissurada, e os núcleos rejeitados em situação de impasse técnico, ou seja, quando não há mais a possibilidade de continuar a debitagem, ou quando não podem mais resultar nos produtos esperados. Uma boa leitura e uma compreensão técnica são assim fundamentais para compreender do que se trata, e não somente descrever e classificar estes seixos como uma quinzena de tipos.

Outro exemplo pessoal foi a observação de algumas dezenas de pontas de flecha arqueológicas. Uma primeira classificação morfológica poderia agrupar uma dezena de formas. Ademais uma observação mais técnica permitiu reconhecer pré-formas abandonadas, inteiras ou deformadas e, ainda, por vezes, quebradas. De fato estavam presentes somente duas formas efetivamente retocadas, as outras peças estavam em diferentes estados técnicos. Assim, de uma dezena de tipos aparentes, teremos somente dois, o que é inclusive mais razoável.

Observamos aqui o duplo interesse desse reconhecimento do estado técnico das peças: um efeito de "purificação" tipológica e também uma informação de ordem econômica.

Contudo é preciso ainda citar uma outra causa de variabilidade aparente: aquela introduzida pela atividade de imitação das crianças e de treinamento de aprendizes, aprendizes esses que são provavelmente jovens adolescentes. Esses comportamentos são completamente previsíveis por duas razões: primeiro, a aprendizagem do lascamento é longa. De acordo com uma pesquisa que fizemos junto aos lascadores amadores modernos, são necessários vários anos, com um treinamento de algumas horas por semana, para chegar a um controle eficaz da fratura concoidal. De fato, lascar exige da mão direita uma precisão milimétrica e da mão esquerda, responsável por apresentar a peça à mão direita, um ajustamento a aproximadamente $50^{\circ}$ de inclinação da peça em relação à direção do golpe. No entanto se essa aprendizagem é longa, isso implica que seus traços de tentativa, seus treinamentos, irão formar uma parte não negligenciável de numerosas coleções.

Em seguida, é bem conhecido que as crianças procuram imitar os mais velhos. Eu não sei se cada um de vocês tem crianças, mas basta observá-las para ver suas tentativas para agir como os adultos, e é difícil imaginar que as crianças fossem impedidas de retomar os núcleos deixados de lado ou abandonados e de tentar alguns golpes, evidentemente, mal executados, cobrindo esses núcleos de acidentes refletidos e esmagamentos do bordo. O reconhecimento de atividade ou imitação por crianças é frequentemente fácil para a fratura concoidal: a imprecisão motora é marcada sobre a ou as últimas superfícies percutidas, através de marcas de impactos infrutuosos, dispersos por vários centímetros quadrados. É bem visível e bem diferente do que um adulto moderno e eficaz faz, que retira uma lasca no máximo no terceiro golpe e chega, desde o segundo, a uma precisão de mais ou menos cinco milímetros em relação ao ponto visado. É claro que a criança não conseguirá destacar corretamente a lasca, mas deixará um 
núcleo marcado por acidentes terminais, tais como: pontos de impacto dispersos, esmagamento de bordo e refletidos repetidos.

O adolescente em seu estado de aprendiz é um pouco mais difícil de ser reconhecido. Sua precisão motora é melhor, mas sua experiência é imatura e será marcada pelas avaliações aproximativas muito otimistas e por uma falta de cuidado e de domínio de si mesmo. Quando um golpe é improdutivo, um lascador experiente vai examinar cuidadosamente o bordo antes de bater novamente ou então vai ajustar a preparação deste bordo. O adolescente, impaciente, vai dar um novo golpe imediatamente, insistindo até esmagar o bordo do plano de percussão ou do esboço façonado. A arqueóloga Nicole Pigeot estabeleceu uma graduação em sete graus de controle do lascamento no sítio pré-histórico de Étiolles, França (margem do rio Sena). O último grau consiste justamente em um controle perfeito de si mesmo, diante de uma dificuldade ou incidente ou mesmo em prevenção de um incidente (PIGEOT, 1987).

Neste caso também, como para a consideração do estado técnico de certas peças, a identificação de atividades de lascadores imaturos tem um efeito saudável de "purificação" tipológica e tecnológica. Para melhor entender o que os pré-históricos procuravam fazer, consideram-se, sobretudo, os instrumentos e as peças façonadas que foram bem realizadas, ou seja, sem acidentes do tipo refletido ou bordo esmagado. Uma peça bem lascada é representativa da intenção subjacente dos lascadores, enquanto uma peça mal lascada não o é.

Pode-se pensar que a existência de crianças e jovens adolescentes é uma evidência, mas reconhecer suas presenças ou ausências em um determinado sítio arqueológico pode ser muito significativo. No sítio Verberie, a aproximadamente $80 \mathrm{~km}$ ao norte de Paris, um acampamento de caça de renas, no vale do rio Oise, o arqueólogo americano Jim Enloe viu um sítio logístico, no sentido de Lewis Binford, onde um grupo de caçadores teria ido para abater as renas e levaram consigo as melhores partes dos animais. Entretanto, a pedido da co-diretora da escavação, Francoise Audouze, analisamos as centenas de núcleos provenientes do principal nível e detectamos precisamente a presença de crianças e de jovens no local. O sítio de Verberie não foi um sítio logístico, mas sim um acampamento residencial (LANGLAIS, no prelo). Recentemente Laurent Klaric (KLARIC, 2018) publicou um conjunto de estudos sobre esse tema na Europa. No mesmo ano no Brasil, a revista da SAB também fez um dossiê temático sobre o assunto (cf. NEUBAUER [org.], 2018; HØGBERG, 2018). Em 2019, Tânia Andrade Lima organizou um pequeno livro sobre o mesmo assunto (LIMA (org.), 2019).

\section{A APREENSÃO DAS INTENÇÕES}

Ainda outro avanço consiste na aplicação da noção recebida da psicologia à análise de atividades de lascamento. A natureza psicológica de intenções, já abordada por Tixier (TIXIER, [1978] 2012), foi refinada, e nós abordaremos aqui um ponto fundamental dessa discussão. Reconhecemos que a maior parte de nossos colegas anglo-saxônicos contesta que as intenções dos grupos pré-históricos sejam acessíveis por nós, ou, ainda, eles contestam a própria noção de intenção. Eles se situam em uma perspectiva "behaviorista", comportamental, segundo a qual as ações não passam de respostas aos estímulos ambientais ou, ademais, de comportamentos aprendidos por imitação, sem projeto definido - como o gato que sai para caçar quando tem fome, e/ou quando a noite cai (VAN PEER \& BAR YOSEF, 2009).

Mas a noção de intenção é incontornável no que se refere às atividades técnicas humanas, pois as atividades técnicas do ser humano não são natas (contrariamente, por exemplo, à construção de ninhos pelos pássaros graveteiros). Além disso, as intenções humanas não são necessariamente originadas por um estímulo ambiental imediato. De 
fato, desde o período do Paleolítico antigo, certos instrumentos são deslocados por alguns quilômetros (FÉBLOT-AUGUSTINS, 1990). Os chimpanzés também são capazes disso, segundo uma observação negligenciada, mas fundamental, do primatólogo Michel Goustard, que merece ser citada: "Um chimpanzé macho adulto foi observado levando com ele seu instrumento (vareta para pegar cupins) na boca e percorreu por volta de 1 quilometro antes de utilizá-lo", o que indica "que ele tem a aptidão de imaginar eventos futuros" (GOUSTARD, 1975:152; 158). Dito de outra forma, tal chipanzé preparou a sua vareta bem antes de "pescar" os cupins, e não depois de ver e reconhecer um cupinzeiro (neste caso, um simples reconhecimento perceptivo de um cupinzeiro poderia despertar uma sequência comportamental imitada: reconhecimento de um cupinzeiro, procura de uma haste vegetal, preparação e utilização no cupinzeiro). De fato, se o chimpanzé preparou uma vareta antes de perceber o cupinzeiro, ele tinha o projeto, a intenção de "pescar" cupins.

Assim, as atividades técnicas humanas não são natas e também não são respostas imediatas frente aos estímulos ambientais. Elas pressupõem uma intenção, uma antecipação ou projeção do resultado esperado de uma ação susceptível de levar a este resultado.

É por isso que é legitimo, para o pré-historiador, considerar que ações técnicas de lascamentos são motivadas por obtenções de peças líticas (suportes utilizáveis brutos ou transformados, peças façonadas) mais ou menos específicas: elas são, em inglês, "goal oriented". O preceito é também admitido pelos adeptos da teoria do design como Hayden et al. (1996), Bleed (1986) ou ainda Catherine Perlès (1992).

Ressalta-se ainda que as modalidades do lascamento são subordinadas às intenções morfológicas e que a intenção ou as intenções da debitagem, quer dizer, a obtenção de suportes que apresentam certos caracteres e/ou dimensões, são articuladas, coerentes com alguns caracteres esperados dos instrumentos, de suas formas e/ou do potencial funcional de seus bordos.

Entretanto isso não implica que as intenções sejam sempre muito específicas. Em uma operação de debitagem, a intenção pode ser sumária, muito pouco especificada. Por exemplo, uma sucessão de golpes monótonos, segundo uma fórmula de agenciamento simples (adjacentes, alternantes, ortogonais), que pode ter tido a intenção de produzir lascas simples, não específicas, conceitualizadas apenas como fragmentos de alguns centímetros, com, pelo menos, um gume cortante, como foi observado em certas debitagens domésticas proto-históricas (PELEGRIN, 2005). Por outro lado, a intenção pode ser muito específica, como a debitagem de grandes lâminas, que requer uma cadeia operatória muito elaborada e que supõe conhecimentos específicos e um savoir-faire consistente $^{4}$ (PELEGRIN, 1985, 1990). Porém, existe uma gama de casos intermediários (PELEGRIN, 2004).

No mínimo, o exemplo supracitado permite reformular o objetivo da caracterização de uma indústria: não tanto descrever e tomar 36 dados sobre cada núcleo, cada

\footnotetext{
${ }^{4}$ Nós definimos como cadeias operatórias elaboradas aquelas que associam as seguintes características (PELEGRIN, 2004):

- quando os processos, ou mesmo o agenciamento de numerosas retiradas, são altamente variáveis em seus detalhes de peça por peça, mas terminam em um resultado similar;

- presença de várias etapas marcadas por mudanças de operação, por exemplo: desbaste, preparação, debitagem, desenvolvimento da debitagem com novas preparações, etc., e/ou técnicas, mudança de percutor, por exemplo;

- produtos finais de debitagem ou de façonagem normatizados ou mesmo estandardizados, segundo certas características independentes da morfologia inicial do material.

Segundo essa definição, podem ser considerados, sem ambiguidade, como cadeias operatórias elaboradas as debitagens Levallois e laminares do período Paleolítico médio e superior, e também um bom número de peças façonadas, tais como as folhas de louro, os bifaces com duplo plano de simetria e bordos alinhados, presentes em certas indústrias acheulenses e mosterienses (BOEDA, GENESTE; MEIGNEN, 1990; BOEDA, 1994; RÉVILLION, 1994; ROCHE \& TEXIER, 1991).
} 
instrumento e resto de lascamento, como o fazem muitos, mas tentar identificar a intenção ou as intenções dos grupos pré-históricos.

Tal modificação de objetivo nos parece fundamental, pois se as modalidades, o que foi realizado, são visíveis, as “intenções e prioridades" não são diretamente.

Vale ressaltar que as indústrias evoluem não somente por:

- adoção de uma inovação, ou seja, novo tipo de instrumento, nova técnica, novo procedimento de encabamento, por exemplo. Esta inovação pode ser endógena (invenção adotada) ou exógena (invenção emprestada);

- ou simetricamente pelo abandono de certas práticas técnicas ou tipos de instrumentos, ou seja, simplificação: um tipo de instrumento pode desaparecer com o desaparecimento de uma atividade específica ou se esta atividade é, a partir de um certo momento, assegurada por um outro tipo de instrumento;

- ou, ainda, as indústrias podem evoluir por uma modificação de prioridades dentro do sistema lítico.

Pode-se complementar tal reflexão afirmando que essa modificação pode ser uma forma de adaptação a uma modificação do modo de exploração do ambiente, o que significa que o primum movens (a primeira motivação) da modificação deverá ser procurado no nível do comportamento dos grupos pré-históricos dentro do seu contexto. Nesse sentido, nós propusemos como o primum movens a transformação ocorrida na prática dominante de caça, para explicar a evolução entre o Magdalenense e o Azilense ${ }^{5}$.

No entanto, em outros casos, na nossa opinião, trata-se de motivos de ordem psicológica e/ou social que determinaram o sucesso de certas inovações ou de classes de instrumentos. Em particular, no caso das peças façonadas bifacialmente, as considerações funcionais ou ergonômicas não são suficientes para explicá-las. Os seres humanos produziram objetos específicos não somente para servir-se deles, mas também com um espírito de competição, ou seja, para mostrar aos outros as suas capacidades, ou, ainda, por auto emulação, ou seja, para dominar a dificuldade. Além disso, para confirmar seu status social.

De toda maneira, não podemos deixar de lado a análise das intenções e das prioridades expressas nas indústrias pré-históricas se quisermos melhor compará-las e distingui-las, ou se quisermos compreender os processos e os sentidos de suas evoluções (para além de notar a substituição de uma tradição por outra, efeito de uma substituição de população: chegada em um determinado espaço de outra etnia trazendo com ela outra

\footnotetext{
${ }^{5}$ De fato, a generalização da debitagem de pequenas lâminas com percussão de pedra macia durante o período Aziliense em detrimento da produção de "grandes" lâminas e lamínulas pode ser vista como a nova prioridade de produzir rapidamente e em abundância os suportes para pontas monolíticas - pequenas pontas à dorso - em resposta a novas modalidades de caça, ocasionando uma taxa de perda importante das pontas. Ao mesmo tempo, a intenção primeira de produção do suporte laminar universal magdalenense foi rapidamente reduzida ou desapareceu. As primeiras lâminas deste tipo de debitagem com pedra macia ou as lâminas de segunda escolha foram utilizadas para produzir os outros instrumentos, diferentes das pontas (PELEGRIN, 2000). Os prenúncios arquezoológicos deste cenário: caça massiva por interceptação de migração ou cerco de renas durante o período Magdalenense - permitindo a recuperação do essencial dos instrumentos lançados; caça de cavalos isolados durante o Aziliense antigo ou durante o Magdalenense com ponta a dorso - ocasionando uma taxa importante de perda de projeteis - foram ulteriormente corroborados pelos estudos de O. Bignon (BIGNON, 2008). B. Valentin, prolongando essa hipótese explicativa, adicionou recentemente que a "degradação" desta debitagem de pequenas lâminas durante o período Aziliense, culminou, no Aziliense recente, a uma debitagem com o simples percutor duro. Isto poderia resultar de uma adaptação a um modo de deslocamento no território errático, não tendo mais acesso assegurado às jazidas de sílex de grãos finos necessários à eficácia de uma percussão tangencial com pedra macia (VALENTIN, 2008a, 2008b).
} 
tradição cultural; ou ainda, os efeitos da mestiçagem cultural, que pode testemunhar a fusão de dois grupos humanos de origens diferentes).

Enfim, podemos nos perguntar como apreender e identificar as intenções da debitagem (ou da façonagem?) em uma coleção, após avaliar o seu estado de conservação, sua integridade e sua homogeneidade arqueológica?

Depois da separação e da primeira classificação dos instrumentos, restos brutos de lascamento, núcleos e eventuais peças façonadas, como já dito, deve-se observar os suportes dos instrumentos (não se esquecendo que certas peças podem ter sido reutilizadas) e suas variações segundo as grandes classes de instrumentos. Por exemplo, para a Europa: raspadores sobre lâminas largas e regulares, buril sobre lâminas espessas, peças com dorso sobre lâmina pouco espessa, etc. Para o Brasil: suportes de lascas com bordo agudo arredondados pela utilização, lascas com coche ou com bordos alterados pela utilização, etc.

Ao mesmo tempo, é necessário observar sobre os núcleos, especialmente aqueles abandonados sem acidentes: seus últimos negativos (retirados com sucesso) e sua morfologia geral - a qual permite de uma certa maneira apreciar as retiradas que foram realizadas - normalmente devem corresponder aos suportes observados nos instrumentos. Ainda, é preciso analisar os restos brutos de lascamento, dentre os quais pode-se encontrar eventuais subprodutos (reparação de plano de percussão, peças com crista), além de produtos de segunda escolha. Ou seja, retiradas obtidas da mesma fase que aquelas que serviram de suporte aos instrumentos, mas "defeituosas" (quebradas durante a debitagem; muito irregulares; muito espessas ou, ao contrário, muito estreitas ou largas demais; com o bordo cortante muito curto ou ainda com demasiado córtex) e por isso não utilizadas. Esses subprodutos e os rejeitos sem alteração macroscópica visível confirmam (por oposição) a especificidade dos "verdadeiros" produtos.

Essa procura das intenções da debitagem e das características correspondentes aos suportes procurados para serem utilizados (retocados ou brutos, estes últimos identificados a partir dos macro-traços de utilização) deve ser realizada caso a caso, olhando cada coleção com um "novo olhar", muito mais que recorrer a uma grade estandardizada de classificação "tecno-morfológica" de lascas debitadas e utilizadas.

O que procuramos identificar é a maneira de ver e de fazer dos grupos préhistóricos, não somente descrever e classificar. Para isso, é preciso considerar as restrições induzidas pela morfologia (forma, dimensões, etc.) e a qualidade dos materiais explorados: de um lado, entender o que oferece a paisagem mineral e seus recursos e, por outro lado, as restrições induzidas pela conformação dos blocos eventualmente escolhidos e efetivamente debitados. É a realização de uma ou de outra opção dentre as diversas possibilidades, que desvendará uma maneira de ver e/ou de fazer específica. De fato, um método de debitagem materializa um compromisso entre o possível (o que permite a matéria-prima) e o desejável (a procura de suportes de tais ou tais características). No entanto, em certos casos, a matéria-prima disponível apresenta tantos limites, que ela oferece um espaço de escolha muito reduzido. Por exemplo, se há somente seixos de quartzo ou de quartzitos arredondados, estes não autorizam muito mais do que uma debitagem limitada de encadeamentos de retiradas.

Em seguida, depois de avaliado o critério restrito ou deliberado da debitagem, é preciso identificar as características mais frequentes, aquelas mais constantes no seio de cada grupo de instrumentos (exemplo: os bordos retocados, os bordos denticulados, os coches, as pontas, os bordos com presença de macrotraços, etc.). Deve-se buscar os princípios ou as regras de seleção dos suportes trabalhados ou utilizados por cada "tipo de instrumento": por exemplo, os bordos retocados principalmente sobre ângulos 
convexos agudos opostos a um dorso espesso; os bordos esmagados sobre lascas pesadas e espessas (talvez utilizados em percussão lançada oblíqua sobre madeira, por exemplo) ${ }^{6}$.

Enfim, nós insistimos, mais uma vez, sobre a necessidade de proceder com um olhar novo, muito mais do que procurar preencher grades pré-existentes. Por exemplo, existem grades de classificação que consideram somente a silhueta da lasca, quadrangular ou quadradas. Como integrar então aqueles suportes com silhuetas triangulares, arredondadas ou em meio-círculo? Diante dessa classificação, elas desaparecerão durante o tratamento de dados ${ }^{7}$. Entretanto, com um novo olhar, estas observações tomam uma nova dimensão, qual seja, aquela de sua própria carga de informação quanto às intenções e às prioridades do grupo pré-histórico que as produziu.

Não falamos aqui da questão da funcionalidade dos instrumentos e de suas diferentes abordagens, incluída aquela de nosso colega Eric Boëda. Quando elas são possíveis, podem ser úteis para completar o método geral apresentado aqui. Entretanto, de toda forma, elas precisam ser confirmadas a partir de um estudo traceológico, tanto no nível macro, quanto no microscópico.

\section{EM CONCLUSÃO}

Então, existe uma tecnologia lítica à francesa? A resposta é... Parece que sim, mas em uma atitude empírica, baseada não sobre modelos teóricos, nem sobre abordagens estatísticas, mas sobre a leitura tecnológica das peças. A prática francesa se enriqueceu de aspectos qualitativos que prolongam a noção de cadeia operatória. Isso permite abordar problemáticas variáveis em duas direções: "econômica" e análise do comportamento técnico, mas também a partir de uma caracterização mais rica, com a preocupação de uma abordagem cultural modernizada, ou seja, passamos de determinações crono-culturais a uma apreciação de similaridades e diferenças no seio das culturas materiais, a fim de interpretar certos aspectos das relações sociais que as ligam(quanto mais intensas são as relações sociais, mais similares são as indústrias entre duas regiões sincrônicas. Entretanto, é preciso realizar essa abordagem a partir de todos os caracteres disponíveis e não somente um. Essa abordagem é evidentemente limitada diante de indústrias simples).

Finalmente, como Jacques Tixier primeiramente nos ensinou, nossa abordagem consiste, graças a uma boa leitura tecnológica e aos conhecimentos preliminares gerais, em compreender antes de classificar e, certamente, antes de medir. Seguramente, esta é a posição mais específica da abordagem francesa das indústrias líticas. Seria como aprender uma língua estrangeira como o russo ou o grego: saber ler os estigmas (reconhecer as letras para "ler" as palavras), conhecer as regras de gramática (apreender os métodos de lascamento), para compreender e apreciar os sentidos (as intenções e as prioridades: conceitos subjacentes à atividade técnica).

\footnotetext{
${ }^{6}$ Em nossa tese de doutoramento sobre o Châtelperroniense, provável última indústria lítica do Homo neandertalense na Europa ocidental, foi possível demonstrar que as truncaturas - criando um ângulo um pouco agudo na extremidade de um bordo cortante -, assim como os coches, foram confeccionadas sobre "suportes não específicos": sem critérios aparentes de seleção, salvo uma dimensão mínima de aproximadamente $3 \mathrm{~cm}$ para transformar a parte ativa procurada, sobre a qual é possível "agir" pegando a peça entre o polegar e o indicador.

${ }^{7}$ Nós nos situamos aqui em um contexto de habitação ou de acampamento com produção e utilização dos produtos líticos in situ, ou ainda com a chegada de instrumentos e suportes utilizados que, em parte, são deixados no local. No caso de coleções líticas provenientes de sítios ditos de "produção lítica" (ou de "atelier", nomenclatura utilizada para o período Neolítico), a proximidade imediata ou sobre uma zona de afloramento de matéria-prima, o raciocínio é um pouco diferente. Neste caso, normalmente serão encontrados poucos instrumentos (eventualmente instrumentos relacionados ao processo de extração para furar o solo ou para transformar os instrumentos de madeira), enquanto os suportes preferencialmente procurados estarão ausentes, pois foram levados.
} 
Sobretudo, é importante insistir no fato de que esses princípios metodológicos não complicaram a expressão dos resultados do estudo de uma coleção, mas, ao contrário, a simplificaram. Após a apresentação das matérias-primas exploradas, se possível discutidas em relação às matérias-primas disponíveis, e a identificação da ou das cadeias operatórias representadas, o que permite elaborar a classificação tecno-econômica do conjunto do material, deve-se apresentar o ou os métodos de lascamento, através de alguns esquemas ilustrados de peças características, em seguida, a ou as técnicas aplicadas, sem necessidade de estatísticas complicadas.

Os resultados de ordem "econômica" remetem às modalidades de ocupação do sítio dentro de um espaço frequentado, ou seja, a função de um sítio no contexto ambiental e sua eventual especialização.

As conclusões propriamente técnicas, qualitativas, que revelam as intenções (maneiras de ver) e as modalidades preferidas tradicionais (maneiras de fazer), participarão das discussões de problemáticas culturais dentro de uma perspectiva comparativa com outras coleções regionais.

Enfim, esta análise pode ocupar algumas poucas páginas de um texto, apoiada por ilustrações de peças significativas, bem escolhidas, e acompanhada por desenhos e fotos representativos do material.

\section{AGRADECIMENTOS}

Agradeço à Professora Mariana Cabral, pelo convite no Congresso da SAB, à Professora Maria Jacqueline Rodet e à doutoranda Déborah Duarte-Talim, pelo trabalho minucioso de tradução, e também ao CNPq e FAPEMIG. 


\section{REFERÊNCIAS BIBLIOGRÁFICAS}

AUBRY, Thierry; WALTER, Bertrand; ROBIN, Emmanuel; PLISSON, Hugues; BENHABDELHADI, Mohammed. 1998. Le site solutréen de plein air des Maitreaux (Bossaysur-Claise, Indre-et-Loire) : un faciès original de production lithique. PALÉO, 10:163-184.

AUDOUZE, Françoise ; SCHLANGER, Nathan (dirs). 2004. Autour de l'homme. Contexte et actualité d'André Leroi-Gourhan. Antibes, Editions APCDA. 442 pp.

BIGNON, Olivier. 2008. Chasser les chevaux à la fin du Paléolithique dans le Bassin parisien. Stratégie cynégétique et mode de vie au Magdalénien et à l'Azilien ancien. Oxford, British Archaeological Reports, Intern. Series 1747, 170 pp.

BINDER, Didier ; PERLÈS, Catherine (avec la collaboration de M.-L. Inizan et M. Lechevallier). 1990. Stratégies de gestion des outillages lithiques au Néolithique. PALÉO, 2:257-283.

BLEED, Peter. 1986. The optimal design of hunting weapons: maintainability or reliability. American Antiquity, 51, 4:737-747.

BOËDA, Eric. 1994. Le concept Levallois: variabilité des méthodes. Paris, CNRS Editions, 280 pp. (Monographie du CRA 9).

BOËDA, Eric; GENESTE, Jean-Michel ; MEIGNEN, Liliane. 1990. Identification de chaînes opératoires du Paléolithique ancien et moyen. PALÉO, 2:43-88.

BOUCHER DE PERTHES, Jacques. 1849. Antiquités celtiques et antédiluviennes : mémoire sur l'industrie primitive et les arts à leur origine. Paris, Treuttel et Würz, Vol. I. 628pp. 80 pl. h.t.

BUENO, Lucas. 2007. Variabilidade tecnológica dos sítios líticos da região do Lajeado, médio rio Tocantins. Revista do Museu de Arqueologia e Etnologia - Universidade de São Paulo, Suplemento 4. $215 \mathrm{pp}$.

CAHEN, Daniel; KARLIN Claudine; KEELEY, Lawrence H.; VAN NOTEN, Francis. 1980. Méthodes d'analyse technique, spatiale et fonctionnelle d'ensembles lithiques. Hélinium, 20:209-259.

CHAUCHAT, Claude; WING, Elizabeth S.; LACOMBE, Jean-Paul; DEMARS, Pierre-Yves; UCEDA, Santiago \& DEZA, Carlos. 1992. Préhistoire de la côte nord du Pérou : Le Paijanien de Cupisnique (Cahiers du quaternaire $n^{\circ} 18$ ), Bordeaux, CNRS Éditions Centre Régional de Publication de Bordeaux. 391pp.

EVANS, Sir John. 1872. The ancient stone implements, weapons and ornaments of Great Britain. New York, D. Appleton. 666pp. (traduzido em françès: 1878 - Les Ages de la pierre. Paris, Germer Baillière, 690pp., 476 fig.)

FEBLOT-AUGUSTINS, Jehanne. 1990. Exploitation des matières premières dans l'Acheuléen d'Afrique : perspectives comportementales. PALEO, 2:27-42.

FOGAÇA, Emílio. 2001. Mãos para o pensamento. A variabilidade tecnológica de indústrias líticas de caçadores-coletores holocênicos a partir de um estudo de caso: as camadas VIII e VII da Lapa do Boquete (Minas Gerais, Brasil - 12.000/10.500 B.P.). Tese de Doutorado. Porto Alegre, Pontifícia Universidade Católica do Rio Grande do Sul. 450pp. 2v.

GAUTHIER, Emmanuelle; PETREQUIN, Pierre. 2017. Interprétations sociales des transferts de grandes haches polies en jades alpins dans l'Europe néolithique. Analyses spatiales dans le cadre du programme ANR JADE 2. ArchéoSciences, Revue d'archéométrie. 41(1):7-23.

GENESTE, Jean-Michel. 1985. Analyse lithique d'industries moustériennes du Périgord: une approche technologique du comportement des groupes humains au Paléolithique moyen. Thèse de Doctorat. Bordeaux : Université de Bordeaux I (Thèse N. D.). 567pp.

GENESTE, Jean-Michel. 1991. Systèmes techniques de production lithique. Variations technoéconomiques dans les processus de réalisation des outillages paléolithiques. Techniques et Culture, 17-18:1-35. 
GOUSTARD, Michel. 1975. Le psychisme des primates. Paris, Masson, 171pp. (Coll. Les grands problèmes de la biologie, Monographie 12)

HAYDEN, Brian; NORA, Franco; SPAFFORD, Jim. 1996. Evaluating lithic strategies and design criteria. In: ODELL, Georges H. (ed). Theory and behavior from stone tools. New York, Plenum Publishing, pp.9-49

HOLMES, William H. 1919. Handbook of aboriginal American antiquities. Part I, Introductory. The lithic industries. Washington: Government printing office, 380 pp. (Smithsonian Institution, Bureau of American Ethnology, Bull. 60).

HØGBERG, Anders. 2018. Approaches to children's knapping in lithic technology studies. Revista de Arqueologia da $S A B, 31,2: 58-74$.

INIZAN, Marie-Louise. 1984. Débitage par pression et standardisation des supports: un exemple capsien au Relilaï (Algérie). In : Préhistoire de la pierre taillée, 2 : économie du débitage laminaire : technologie et expérimentation: IIIe table ronde de technologie lithique. Meudon-Bellevue, octobre 1982. Paris, Cercle de Recherches et d'Etudes Préhistoriques, 1984, p. 85-92.

INIZAN, Marie-Louise; REDURON-BALLINGER, Michèle; ROCHE, Hélène ; TIXIER, Jacques. 1995. Technologie et terminologie de la Pierre taillée (Préhistoire de la pierre taillée, 4, suivi d'un vocabulaire multilingue). Meudon-Bellevue, CREP, publié en ligne sur le site de la MAE. https://www.researchgate.net/publication/241685466_Technologie_de_la_pierre_taillee

INIZAN, Marie-Louise; REDURON-BALLINGER, Michèle; ROCHE, Hélène \& TIXIER, Jacques. 1999. Technology and Terminology of knapped stone (Préhistoire de la pierre taillée, 5, followed by a multilingual vocabulary). CREP, Nanterre, 189pp. published online 2009 on the MAE website. (traduction of the French 1995 edition).

INIZAN, Marie-Louise; REDURON-BALLINGER, Michèle; ROCHE, Hélène \& TIXIER, Jacques. 2017. Tecnologia da Pedra Lascada, Edição 1995 revisada, atualizada e ampliada com definições e exemplos brasileiros par M.-J. Rodet \& J. de Resende Machado. Belo Horizonte, Museu de História Natural e Jardim Botânico de UFMG (Universidade Federal de Minas Gerais). 210pp.

KEELEY, Lawrence H. 1980. Experimental determination of stone tool uses. Chicago, The University of Chicago Press. 226pp.

KLARIC, Laurent (ed.). 2018. The prehistoric apprentice: investigating apprenticeship, know-how and expertise in prehistoric technologies / L'apprenti préhistorique: appréhender l'apprentissage, les savoirfaire et l'expertise à travers les productions techniques des sociétés préhistoriques. Brno, The Czech Academy of Sciences, Institute of Archaeology. 375pp., em français \& English (The Dolni Vestonice studies, vol. 24).

LEMONNIER, Pierre. 1992. Elements for an anthropology of technology. Ann Arbor: University of Michigan. 129pp. (Anthropological papers, $n^{\circ} 88$ ).

LIMA, Tania A. (org.). 2019. (In)visibilidade de crianças no registro arqueológico. Rio de Janeiro, Museu Nacional / UFRJ. 92 p. (Série Livros, 63).

LOURDEAU, Antoine. 2010. Le techonocomplex Itaparica: définition tecno-fonctionnelle des industries a pièces façonnées unifacialement à une face plane dans le centre e le nord-est du Brésil pendant la transition Pléistocène-Holocène e Holocène ancien. Tese de Doutorado. Paris, Université de Paris Ouest Nanterre La Defense. 477pp.

MAGET, Marcel. 1953 Guide d'étude directe des comportements culturels. Paris, Editions des civilisations du Sud. 278pp.

MAUSS, Marcel. 1947. Manuel d'ethnographie. Paris, Petite Bibliothèque Payot. 211pp.

MÜLLER, Hippolyte 1903. Essais de taille du silex: montage et emploi des outils obtenus. L’Anthropologie, XIV:417-436. 
NEUBAUER, Fernanda. 2018. Uma criança brasileira nasce: introdução ao dossiê temático sobre a Arqueologia da Infância. Revista de Arqueologia da SAB, 31, 2:2-13.

PELEGRIN, Jacques. 1985. Réflexions sur le comportement technique. In : OTTE, Marcel (ed.). La signification culturelle des industries lithiques. Studia Praehistorica 4, BAR International Series 239. pp.72-91 (actes du colloque de Liège, UISPP 8ème com., oct. 1984).

PELEGRIN, Jacques. 1990. Prehistoric lithic technology: some aspects of research. Archeological Review from Cambridge, 9, 1:116-125 (special Nr "Technology in the humanities" Schlanger N. ed.).

PELEGRIN, Jacques. 1991. Aspects de démarche expérimentale en technologie lithique. In: Centre de Recherche Archéologiques du CNRS (org.). 25 ans d'études technologiques en Préhistoire: bilan et perspectives, Actes des XIèmes rencontres internationales d'Archéologie et d'Histoire d'Antibes. Juan-les-Pins, APDCA. pp 57-63.

PELEGRIN, Jacques. 2000. Les techniques de débitage laminaire au Tardiglaciaire : critères de diagnose et quelques réflexions. In: VALENTIN, Boris; BODU, Pierre; CHRISTENSEN, Marianne (eds.) - L'Europe centrale et septentrionale au Tardiglaciaire. Confrontation des modèles régionaux de peuplement. Nemours, APRAIF (actes de la table-ronde de Nemours, mai 1997. Mémoire du Musée de Préhistoire d'Ile-de-France, 7), pp.73-86.

PELEGRIN, Jacques. 2004. Le milieu intérieur d'André Leroi-Gourhan et l'analyse de la taille de pierre au Paléolithique. In: AUDOUZE, Françoise \& SCHLANGER Nathan (dirs). 2004. Autour de l'homme. Contexte et actualité d'André Leroi-Gourhan. Antibes, Editions APCDA. pp.149-162 (+ referências bibliográficas no final da obra).

PELEGRIN, Jacques. 2005. Remarks about archaeological techniques and methods of knapping: elements of a cognitive approach to stone knapping. In: ROUX, Valentine. \& BRIL, Blandine. (eds). Stone knapping: the necessary condition for a uniquely hominid behaviour. Cambridge, Mac Donald Institute monograph series, pp.23-33.

PELEGRIN, Jacques. 2012a. New Experimental Observations for the Characterization of Pressure Blade Production Techniques. In: DESROSIERS, Pierre (ed.) The Emergence of Pressure Blade Making: From Origin to Modern Experimentation. New York, Springer Editions (Springer Science + Business Media, LLC 2012), pp.465-500.

PELEGRIN, Jacques. 2012b. Sur les débitages laminaires du Paléolithique supérieur. In: JAUBERT, Jacques \& DELPECH, Françoise (dirs.) François Bordes et la Préhistoire. Paris, Editions du Comité des travaux historiques et scientifiques, pp.141-152 (Documents préhistoriques, 29).

PELEGRIN, Jacques; TEXIER, Pierre-Jean. 2004. Les techniques de taille de la pierre. Les Dossiers d'Archéologie, nº spécial thématique 290:26-33.

PIGEOT, Nicole. 1987. Magdaléniens d'Etiolles, Économie de débitage et organisation sociale (l'unité d'habitation U5). Paris, Editions du CNRS (Gallia Préhistoire, supplément XV), 168 pp.

PERLÈS, Catherine. 1980. Economie du débitage et économie des matières premières : deux exemples grecs. In: TIXIER, Jacques (dir.) Préhistoire et technologie lithique, Paris, Editions du CNRS, pp.37-41 (Cahier n 1 de l'URA 28).

PERLÈS, Catherine. 1990. L'outillage de pierre taillée néolithique en Grèce : approvisionnement et exploitation des matières premières. Bulletin de Correspondance Hellénique CXIV, 1:1-42.

PERLÈS, Catherine. 1992. In search of lithic strategies: a cognitive approach to prehistoric chipped stone assemblages. In: GARDIN, Jean-Claude \& PEEBLES, Christopher S. (eds.) Representations in Archaeology. Bloomington, IN, Indiana University Press, pp.223-247.

PERLÈS, Catherine. 2016. La technologie lithique, de part et d'autre de l'Atlantique. Bulletin de la Société préhistorique française, tome 113, 2:221-240.

PROUS, André. 1986. Os artefatos líticos, elementos descritivos classificatórios. Arquivos do Museu de História Natural, v. 11:1-90. 
PROUS, Andre; FOGAÇA, Emilio; LIMA, Marcio A. 1994. As últimas indústrias líticas do vale do Peruaçu, MG. Revista de Arqueologia, São Paulo, Sociedade de Arqueologia Brasileira, 8 (2) : 4964.

REVILLION, Stéphane. 1994. Les industries laminaires du Paléolithique moyen en Europe septentrionale. Lille, Publications du CERP (Centre d'Etudes et de Recherche Préhistoriques), Université des Sciences et Technologies de Lille, n 5, 187pp.

ROCHE, Hélène ; TEXIER, Pierre-Jean 1991. La notion de complexité dans un ensemble lithique: application aux séries acheuléennes d'Isenya (Kenya). In: Centre de Recherche Archéologiques du CNRS (org.). 25 ans d'études technologiques en Préhistoire: bilan et perspectives. (Actes des XIe rencontres internationales d'Archéologie et d'Histoire d'Antibes). Juan-les-Pins, APDCA, pp.99-108.

RODET, Maria Jacqueline. 2006. Étude Technologique des industries lithiques taillées du nord de Minas Gerais, Brésil : depuis le passage Pléistocène/Holocène jusqu'au contact - XVIIIème siècle. Thèse de Doctorat, Université Paris X - Nanterre. 516pp.

RODET, Maria Jacqueline; DUARTE-TALIM, Déborah; SANTOS JUNIOR, Valdeci dos. 2013. Cadeia operatória e análise tecnológica: uma abordagem metodológica possível para as indústrias líticas lascadas da América do Sul (exemplo das pontas de projétil do nordeste do Brasil). Cuadernos del Instituto Nacional de Antropologia, v. 2:264-278.

RODET, Maria Jacqueline; DUARTE-TALIM, Déborah; SCHMITZ, P.I. 2019. As indústrias antigas de Serranópolis (sítios GO-JÁ-03 d GO-JÁ-14). In: Revista de Arqueologia. V. 32. No.1: 175-206.

ROUX, Valentine. 2016. Des céramiques et des hommes. Décoder les assemblages archéologiques (en coll. avec M.-A. Courty). Nanterre, Presses universitaires de Paris-Nanterre. 415 pp., ill. couleurs.

ROUX, Valentine. 2019. Ceramics and Society. A Technological Approach to Archaeological Assemblages (with the collaboration of M.-A. Courty). Springer Nature Switzerland AG, 329 pp.

SCHLANGER, Nathan. 2005. The Chaîne opératoire. In: RENFREW, Colin \& BAHN, Paul (eds.). Archaeology: The Key Concepts. London, Routledge, pp. 25-31.

SEHESTED, Nils F.B. 1884. Archaeologiske Undersoegelser 1878-1881. Copenhagen, pp.1-40.

SEMENOV, Sergey A. 1964 - Prehistoric technology: an experimental study of the oldest tools and artefacts from traces of manufacture and wear. London, Cory, Adams et Mackay. 211 pp.

SORESSI, Marie; GENESTE, Jean-Michel. 2011. The History and Efficacy of the Chaîne Opératoire Approach to Lithic Analysis: Studying Techniques to Reveal Past Societies in an Evolutionary Perspective. PaleoAnthropology pp.334-350 (Special Issue: TOSTEVIN, Gilbert B. (ed) Reduction Sequence, Chaîne opératoire, and Other Methods: The Epistemologies of Different Approaches to Lithic Analysis), (on line from the PaleoAnthropology Society doi:10.4207/PA.2011.ART63).

TIXIER, Jacques. 1967. Procédés d'analyse et questions de terminologie concernant l'étude des ensembles industriels du Paléolithique récent et de l'Epipaléolithique dans l'Afrique du NordOuest. In: BISHOP, Walter W. \& DESMOND-CLARK, John (eds.). Back-ground to evolution in Africa. Proceedings of a symposium held at Burg Wartenstein Austria, July-August 1965. Chicago, University of Chicago Press, pp.771-820.

TIXIER, Jacques. 1976. L'industrie lithique capsienne de l'Aïn Dokkara, Région de Tébessa, Algérie. Lybica, t. XXIV: 21-53.

TIXIER, Jacques. 1980. Raccords et remontages. In: Tixier, Jacques (org.) 1980. Préhistoire et technologie lithique. Journées du 11-12-13 mai 1979. Valbonne, Sophia Antipolis, CNRS, 59 p. (Cahier n 1 de l’URA 28). (Réimpression 1984, Paris, CNRS). pp. 50-55. 
TIXIER, Jacques. 1982. Techniques de débitage: osons ne plus affirmer. In: CAHEN, D. (ed.). Tailler! pour quoi faire: Préhistoire et technologie lithique II. Recent progress in microwear studies. Studia Praehistorica Belgica 2. Tervuren pp.3-22.

TIXIER, Jacques. 2012. A method for the study of stone tools - méthode pour l'étude des outillages lithiques: guidelines based on the work of J. Tixier - notice sur les travaux scientifiques de J. Tixier, Luxembourg, Musée National d'Histoire et d'Art / Centre National de Recherche Archéologique, 197 pp. (ArchéoLogiques ; 4).

TIXIER, Jacques; INIZAN, Marie-Louise; ROCHE, Hélène. 1980. Préhistoire de la pierre taillée 1: terminologie et technologie. Paris, Éditions Cercle de Recherches et d'Etudes Préhistoriques.123pp.

TUFFREAU, Alain (dir.). 1993. Riencourt-les-Bapaume (Pas-de-Calais). Un gisement du Paléolithique moyen. Paris, Editions de la Maison des Sciences de l'Homme, Documents d'Archéologie Française, $\mathrm{n}^{\circ} 37,126 \mathrm{pp}$.

VALENTIN, Boris. 2008a - Jalons pour une paléohistoire des derniers chasseurs (XIV-VIe millénaire avant J.-C. Paris, Publications de la Sorbonne, 325 pp. (Cahiers archéologiques de Paris I- 1, Univ. Paris I - Panthéon-Sorbonne).

VALENTIN, Boris. 2008b. Productions lithiques magdaléniennes et aziliennes dans le Bassin parisien : disparition d'une économie programmée. The Arkeotek Journal, Vol. 2, n³: 24p. Disponível http://www.thearkeotekjournal.org/tdm/Arkeotek/fr/archives/2008/3Valentin.xml

VAN PEER, Philip; BAR-YOSEF, Ofer. 2009. The Chaîne Opératoire Approach in Middle Paleolithic Archaeology. Current Anthropology, 50, 1:103-131. (DOI : 10.1086/592234).

VASIL'EV, Sergey. 2011. La Préhistoire russe et François Bordes : les influences réciproques. In: DELPECH, Françoise \& JAUBERT, Jacques (dirs.). François Bordes et la Préhistoire. Colloque international François Bordes, Bordeaux, 22-24 avril 2009. Paris, Editions du Comité des travaux historiques et scientifiques, pp.71-84. (Documents préhistoriques, 29). 